\title{
Risk of QT-Interval Prolongation From Off-Label COVID-19 Treatments: A Single-Center Experience
}

\author{
Natalia Reborido Campoy, MD ${ }^{1} \bullet$ Kevin Ball, MD² $\bullet$ Todd Foster, PhD³ $\bullet$ Kathleen L. Morris, DO² $\bullet$ Sandeep Joshi, MD² $\bullet$ Emily Cochard, MD
}

\section{ABSTRACT:}

Background. During the COVID-19 pandemic, researchers continue to search for effective treatments. There have been mixed data on the safety and effectiveness of hydroxychloroquine (HCQ). Risk assessment is essential to identify patients who might be at high risk for complications from treatment.

Objectives. The purpose of this study was to evaluate patients with confirmed or suspected COVID-19 treated with HCQ for risk of QT-interval prolongation and drug-induced sudden cardiac death (DI-SCD).

Methods. A total of 100 patients admitted to the intensive or progressive care units at Ascension St. Vincent Hospital in Indianapolis, Indiana, between March 2020 and April 2020 with confirmed or suspected COVID-19 who were treated with $\mathrm{HCQ}$ were identified. Risk stratification was performed using the Ackerman algorithm. Serial electrocardiography (ECG) monitoring and 24-hour cardiac monitoring were completed.

Results. According to the Ackerman algorithm, 80 (85.1\%) of the 94 patients with ECG data were at low risk for corrected QT (QTc) interval prolongation (green category), 12 (12.8\%) were intermediate risk (yellow category), and $2(2.1 \%$ ) were high risk (red category). Change in QTc interval greater than $60 \mathrm{~ms}$ from initial to 48 hours was noted in 15 patients (16.0\%). No events of DI-SCD were reported in patients in the green or yellow categories. DI-SCD was confirmed in 1 patient in the red category, with a QTc-interval prolongation greater than $60 \mathrm{~ms}$.

Conclusions. Although treatment with this regimen remains controversial, the risk of DI-SCD is low in patients who have been risk-stratified to be at low or intermediate risk based on the Ackerman algorithm.

KEYWORDS: COVID-19, hydroxychloroquine, QT-interval prolongation, drug-induced sudden cardiac death (DI-SCD)

\section{AFFILIATIONS}

${ }^{1}$ Department of Internal Medicine, Ascension St. Vincent Hospital, Indianapolis, Indiana

2Department of Cardiology, Ascension St. Vincent Hospital, Indianapolis, Indiana ${ }^{3}$ Medical Education, Ascension St. Vincent Hospital, Indianapolis, Indiana ${ }^{4}$ Departments of Pulmonology and Critical Care, Ascension St. Vincent Hospital, Indianapolis, Indiana

\section{CITATION:}

Reborido Campoy N, Ball K, Foster T, Morris KL, Joshi S, Cochard E. Risk of QT-interval prolongation from off-label COVID-19 treatments: a single-center experience. Consultant. 2021;61(1):3-5, 12-13, 16.

doi:10.25270/con.2020.10.00011

Received July 22, 2020. Accepted September 8, 2020.

\section{DISCLOSURES:}

The authors report no relevant financial relationships.

\section{CORRESPONDENCE:}

Natalia Reborido Campoy, MD, Ascension St. Vincent Hospital Department of Internal Medicine, 3 North, 2001 W 86th St, Indianapolis, IN 46260 (natalia. reborido.campoy@ascension.org)
0 n March 11, 2020, the World Health Organization (WHO) characterized COVID-19 as a pandemic. The SARS-CoV-2 virus has killed hundreds of thousands of people throughout the world as the scientific community has attempted to find an effective treatment. In vitro data and small clinical studies had suggested that off-label use of hydroxychloroquine (HCQ) with or without the addition of azithromycin $(\mathrm{H} \pm \mathrm{A})$ may have a positive therapeutic effect in cases of COVID-19. . $^{1-6}$

In the early COVID-19 era, many centers were administering $\mathrm{H} \pm \mathrm{A}$ to most patients presenting with severe respiratory symptoms due to confirmed or suspected COVID-19. These two drugs are known blockers of the human ether-a-go-go-related gene ( $h E R G$; preferred name, $K C N H 2$ [potassium voltage-gated channel subfamily $\mathrm{H}$ member 2]), causing QT-interval prolongation that can lead to fatal cardiac arrhythmias such as torsade de pointes/ventricular fibrillation (TdP/VF) ${ }^{7,8}$

To better assist health care providers mitigate the QT-interval prolongation risk, the Mayo Clinic provided an algorithm 


\section{Risk of QT-Interval Prolongation From Off-Label COVID-19 Treatments: A Single-Center Experience}

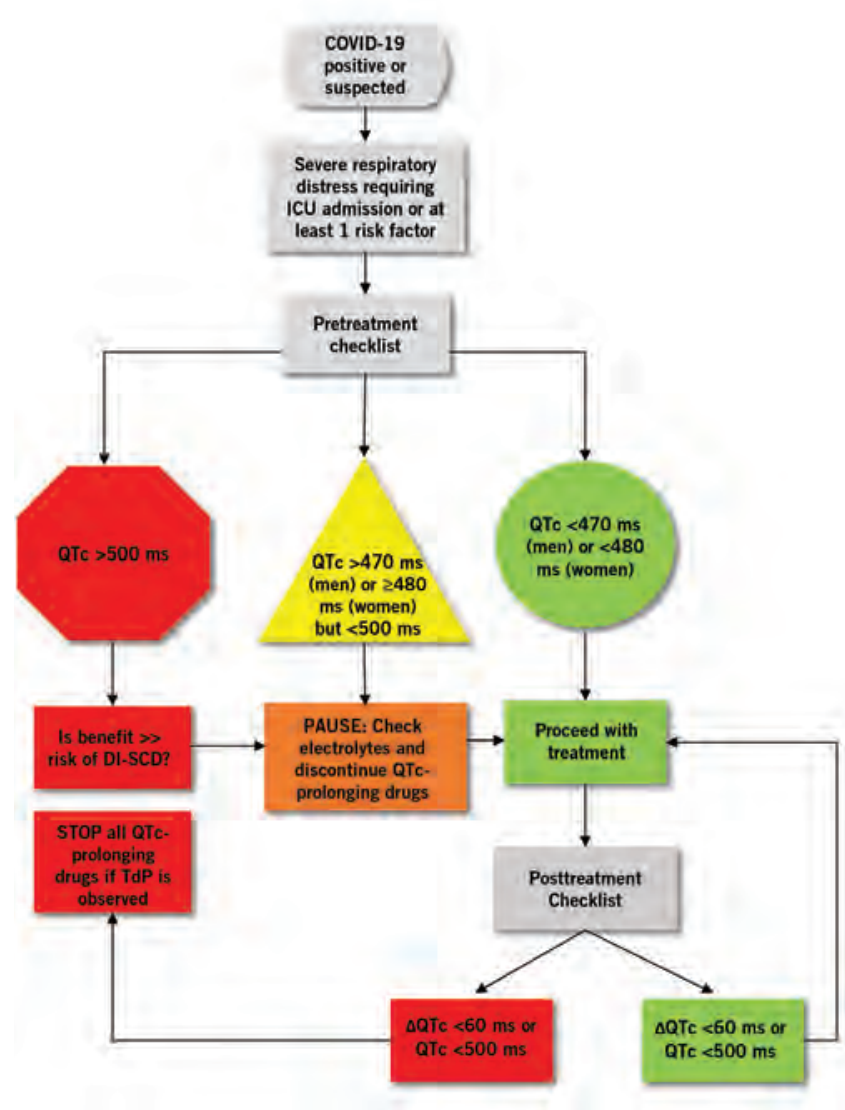

Figure. Algorithm based on the Ackerman algorithm to assess DI-SCD risk in patients with confirmed or suspected COVID-19 who are candidates for $\mathrm{H} \pm \mathrm{A}$ off-label treatment. It applies to patients with confirmed or suspected COVID-19 who require ICU care or have at least one of the following risk factors: age $>65$ years, immunosuppression, or high-risk comorbidities. It proposes a pretreatment assessment based on baseline QTC (Bazett formula): those with a QTc $>500$ ms will be considered at high risk for DI-SCD (categorized as red), and risk of DI-SCD may overcome the benefits. Patients with an initial QTC $>470 \mathrm{~ms}$ (men) or $\geq 480 \mathrm{~ms}$ (women) but $<500 \mathrm{~ms}$ will be considered intermediate risk (categorized as yellow), and they may proceed with treatment, but while making sure that the potassium level is $>4 \mathrm{mEq} / \mathrm{L}$, the magnesium level is $>2 \mathrm{mg} / \mathrm{dL}$, and unnecessary QT prolonging drugs are discontinued. Patients with a QTc $<470 \mathrm{~ms}$ (men) or $<480 \mathrm{~ms}$ (women) are considered to have a low risk of DI-SCD (categorized as green), and treatment can be safely started. In all cases, posttreatment assessment with periodic QTc assessment and electrolytes surveillance must be done. If significant QTc prolongation and/or TdP occurs, treatment should be discontinued.
(Figure) developed byx Michael J. Ackerman, MD, PhD, and colleagues to assess drug-induced sudden cardiac death (DI-SCD) risk in patients with confirmed or suspected COVID-19 who are candidates for $\mathrm{H} \pm \mathrm{A}$ off-label treatment. ${ }^{8}$ Overall, there are very limited data regarding the risk of DI-SCD with these drugs, particularly in critically ill patients. Thus, it is essential to identify risk of DI-SCD and the true incidence of QT-interval prolongation in patients undergoing treatment with $\mathrm{H} \pm \mathrm{A}$.

The purpose of this study is to retrospectively risk-stratify patients based on the Ackerman algorithm and then, based on this risk, look at mean change in QTc interval along with the risk of developing a drug-related arrhythmia.

\section{METHODS}

This is a retrospective, single-center descriptive analysis conducted at Ascension St. Vincent Hospital in Indianapolis, Indiana, according to institutional board review standards. The study included 100 patients, 87 of whom were admitted to the intensive care unit (ICU) and 13 to the progressive care unit (PCU). All 100 presented with severe respiratory symptoms defined as the presence of acute hypoxic respiratory failure (AHRF) and/or acute respiratory distress syndrome (ARDS). ${ }^{9}$ All patients underwent nasopharyngeal swab testing for COVID-19 by polymerase chain reaction (PCR) before or at the time of admission.

All 100 patients, whether they were confirmed or suspected to be COVID-19-positive, received HCQ, $400 \mathrm{mg}$ twice daily, with or without azithromycin, $500 \mathrm{mg}$ daily, for the first day, with most patients (70) continuing HCQ, $400 \mathrm{mg}$ daily, for a total of 5 days with or without azithromycin, $250 \mathrm{mg}$ daily, for 3 to 5 days. Treatment was guided and monitored by an infectious disease team with the assistance of pharmacists. Generally, electrocardiograms (ECGs) were obtained at the initiation of treatment and at 48 hours, 5 days, and 10 days from the beginning of treatment. All ECGs were reviewed by a cardiologist. The corrected QT (QTc) interval was calculated using the Bazett formula, and necessary corrections for QRS complexes greater than $120 \mathrm{~ms}$ were performed. QTc interval prolongation and absolute variation of the QTc interval $(\Delta \mathrm{QTc})$ were calculated for all patients. All patients had 24-hour continuous ECG monitoring by telemetry.

The Ackerman algorithm was retrospectively applied, and patients were stratified into green (low risk), yellow (intermediate risk), or red (high risk) categories. Based on the algorithm criteria, 6 patients had incomplete ECG data; thus, 94 of the 100 patients were categorized by risk. We collected baseline characteristics for all patients, including age, sex, and comorbidities. In addition, we collected information on supplemental variables including electrolytes, with potassium, magnesium, and calcium levels measured at baseline, 48 hours, 72 hours, and 5 days of treatment, along with any concomitant use of other QTc-prolonging drugs (Table 1). We subsequently col- 
Table 1. Drugs That Prolong QT Interval and Are Associated With Risk of TdP, Even When Taken as Recommended. ${ }^{?}$

Ciprofloxacin

Citalopram

Domperidone

Escitalopram

Flecainide

Fluconazole

Haloperidol

Levofloxacin

Ondansetron

lected the QTc interval from ECGs, along with any documented arrhythmias and arrhythmic events.

Descriptive statistics, including counts and rates, are presented for all patients as well as those classified into red, yellow, or green risk categories using the Ackerman algorithm. All demographics, clinical presentations, and comorbidities are displayed in this way. The count and rate of arrhythmic events and cardiac arrest among the risk classifications is presented in this manner, as well. Associated variables such as potassium, magnesium, and calcium levels are also presented with descriptive statistics.

Only 2 patients in our planned sample were classified in the high-risk or red category. These patients' data were available for the initial, 48-hour, and 5-day measurements of QTc interval (Table 2). A one-sample $t$-test was used to compare the red category values with the green and yellow category values. When both red category patient values were available, their average was calculated to be used as the red category proxy. This red category proxy, or test value, was compared with the values for the yellow category alone, the green category alone, and the yellow and green categories combined. One-sample $t$-tests can be completed for randomly selected, continuous variables between independent samples. The QTc variables among the sampled categories were reviewed for outliers and for normal distribution. The authors acknowledge the limitations of the findings of these one-sample $t$-tests. Nevertheless, these one-sample $t$-tests were completed for hypothetical comparisons and to generate possible future hypotheses. Independent-samples $t$-tests were used to compare QTc interval values between the yellow and green categories. A $P$ value of less than .05 was considered statistically significant for these completed inferential tests. IBM SPSS Statistics 24.0 was used to complete all statistics in this study.

\section{RESULTS}

Of the 100 patients treated with $\mathrm{HCQ}, 73$ had positive COVID-19 PCR testing. Eighteen patients were PCR-negative, 5 tests were pending at time of data collection, and 4 test results were missing. Women comprised $44 \%$ of the patients, and $34 \%$ of all patients were 68 years of age or older. The mean age was 58.7 years (standard deviation [SD], 15.8 years), with a range from 21 to 92 years old. The mean body mass index was 32.6 $\mathrm{kg} / \mathrm{m}^{2}\left(\mathrm{SD}, 9.2 \mathrm{~kg} / \mathrm{m}^{2}\right)$. Baseline demographic data and comorbidities are presented in Table 3. Thirty-five percent of patients died, 34\% were discharged home from the hospital, 14\% were discharged to a long-term acute-care facility, and 17\% remained in the hospital at the time of data acquisition.

All patients $(\mathrm{N}=100)$ received $\mathrm{HCQ}$, and 67 also received azithromycin. Eight patients were receiving loop diuretics at home, and 72 patients received loop diuretics during hospitalization. Thirty-eight patients were on medications known to prolong the QT interval, 2 were in the red category, 5 were in the yellow category, and 31 were in the green category. The mean initial potassium level was $4.1 \mathrm{mEq} / \mathrm{L}(\mathrm{SD}, 0.7 \mathrm{mEq} / \mathrm{L})$, the mean initial magnesium level was $3.3 \mathrm{mg} / \mathrm{dL}$ (SD, 11.3 $\mathrm{mg} / \mathrm{dL}$ ), and the mean initial calcium level was $8.7 \mathrm{mg} / \mathrm{dL}$ $(\mathrm{SD}, 0.5 \mathrm{mg} / \mathrm{dL})$.

ECG data were available for 94 of the 100 patients. Of the 94 patients with ECG data, 74 (78.8\%) had ECG data available at 48 hours, $62(66.0 \%)$ at 5 days, and $21(22.3 \%)$ at 10 days from the start of treatment. The mean initial QTc interval was $441.7 \mathrm{~ms}$ (range, 254-555 ms; SD, $42 \mathrm{~ms}$ ). The mean QTc interval at 48 hours was $450.5 \mathrm{~ms}$ (range, 343-636 ms; SD, $46.8 \mathrm{~ms}$ ), at 5 days was $454.9 \mathrm{~ms}$ (range, 377-569 ms; SD, $33.5 \mathrm{~ms}$ ), and at 10 days was $460.1 \mathrm{~ms}$ (range, 409-550 ms; SD, $37.7 \mathrm{~ms}$ ). The mean change in QTc interval from initial to 48 hours was $8.6 \mathrm{~ms}$

\section{Table 2. QTC Interval (ms) Values for Red Category Patients ( $\mathrm{n}=2$ )}

\begin{tabular}{|l|l|l|l|l|l|l|l|}
\hline & Initial QTc & QTc at 48 h & QTc at 5 d & QTc at 10 d & $\begin{array}{l}\Delta \text { QTc } \\
\text { (Initial-48 h) }\end{array}$ & $\begin{array}{l}\Delta \text { QTc } \\
\text { (Initial-5 d) }\end{array}$ & $\begin{array}{l}\Delta \text { QTC } \\
\text { (Initial-10 d) }\end{array}$ \\
\hline Patient 1 & 555 & NA & 569 & NA & NA & -14 & NA \\
\hline Patient 2 & 512 & 630 & NA & NA & -118 & NA & NA \\
\hline $\begin{array}{l}\text { Average (OR value to be used } \\
\text { for red one-sample t-test } \\
\text { estimate) }\end{array}$ & 533.5 & 630 & 569 & NA & -118 & -14 & NA \\
\hline
\end{tabular}


Risk of QT-Interval Prolongation From Off-Label COVID-19 Treatments: A Single-Center Experience

Continued from page 5

\begin{tabular}{|c|c|c|}
\hline Demographics $(\mathrm{N}=100)$ & Number & $\%$ \\
\hline Female & 44 & 44 \\
\hline Age $>68$ y & 34 & 34 \\
\hline African American & 43 & 43 \\
\hline White & 50 & 50 \\
\hline Other race/ethnicity & 7 & 7 \\
\hline Admitted to ICU & 87 & 87 \\
\hline Admitted to PCU & 13 & 13 \\
\hline $\begin{array}{l}\text { COVID-19 Status } \\
(\mathrm{N}=100)\end{array}$ & Number & $\%$ \\
\hline Positive & 73 & 73 \\
\hline Negative & 18 & 18 \\
\hline Pending & 5 & 5 \\
\hline Missing & 4 & 4 \\
\hline Comorbidities ( $\mathrm{N}=100)$ & Number & $\%$ \\
\hline COPD & 16 & 16 \\
\hline Asthma & 10 & 10 \\
\hline Other lung disease & 2 & 2 \\
\hline CAD & 25 & 25 \\
\hline Pulmonary HTN & 4 & 4 \\
\hline HFpEF & 16 & 16 \\
\hline HFrEF & 5 & 5 \\
\hline $\begin{array}{l}\text { LVEF, number, mean } \\
\text { (SD) }\end{array}$ & 40 & $58(0.09)$ \\
\hline HTN & 66 & 66 \\
\hline Type 2 diabetes & 26 & 26 \\
\hline Type 1 diabetes & 11 & 11 \\
\hline Immunosuppression & 7 & 7 \\
\hline
\end{tabular}

(SD, $53.4 \mathrm{~ms}$ ), initial to 5 days was $13.4 \mathrm{~ms}$ (SD, $40.3 \mathrm{~ms})$, and initial to 10 days was $17.6 \mathrm{~ms}$ (SD, $43.4 \mathrm{~ms}$ ) (Table 4).

Of the 94 patients with ECG data stratified using the Ackerman algorithm, 80 patients $(85.1 \%)$ were in the green category, 12 patients $(12.8 \%)$ were in the yellow category, and 2 patients $(2.1 \%)$ were in the red category. Fifteen patients $(16 \%)$ had a change in QTc interval greater than or equal to $60 \mathrm{~ms} ; 1(6.7 \%)$ of these 15 patients was in the red category, $2(13.3 \%)$ were in the yellow category, and $12(80.0 \%)$ were in the green category.

Table 5 displays the results for the QTc interval (ms) values for the red category proxy or test value compared with the mean for green only, yellow only, and green and yellow combined categories.
Table 3. Baseline Characteristics of Patients

\begin{tabular}{|c|c|c|}
\hline Medications & Number & $\%$ \\
\hline $\begin{array}{l}\text { Loop diuretic (home } \\
\text { medication) }\end{array}$ & 8 & $\begin{array}{l}8.1 \text { (based on } \\
96 \text { patients) }\end{array}$ \\
\hline $\begin{array}{l}\text { Loop diuretic } \\
\text { (in hospital) }\end{array}$ & 72 & 72 \\
\hline $\begin{array}{l}\text { At least } 1 \text { QT-prolonging } \\
\text { drug at admission }\end{array}$ & 38 & $\begin{array}{l}40.4 \text { (based on } \\
96 \text { patients) }\end{array}$ \\
\hline $\mathrm{HCQ}$ & 100 & 100 \\
\hline HCQ+azithromycin & 67 & 67 \\
\hline $\begin{array}{l}\text { Ackerman Category } \\
(n=94)\end{array}$ & Number & $\%$ \\
\hline Red & 2 & 2.1 \\
\hline Yellow & 12 & 12.8 \\
\hline Green & 80 & 85.1 \\
\hline $\begin{array}{l}\text { Tisdale Risk Score for } \\
\text { QT Prolongation }(n=99)\end{array}$ & Number & $\%$ \\
\hline$\leq 6$ (low risk) & 78 & 78.8 \\
\hline 7-10 (intermediate risk) & 20 & 20.2 \\
\hline$\geq 11$ (high risk) & 1 & 1 \\
\hline $\begin{array}{l}\text { Baseline Laboratory } \\
\text { Values }(\mathrm{N}=100)\end{array}$ & Number & Mean (SD) \\
\hline Initial potassium & 100 & $\begin{array}{l}4.1 \mathrm{mEq} / \mathrm{L} \\
(0.7)\end{array}$ \\
\hline Initial magnesium & 80 & $\begin{array}{l}3.3 \mathrm{mg} / \mathrm{dL} \\
(11.3)\end{array}$ \\
\hline Initial calcium & 100 & $\begin{array}{l}8.7 \mathrm{mg} / \mathrm{dL} \\
(0.5)\end{array}$ \\
\hline
\end{tabular}

Abbreviations: CAD, coronary artery disease; COPD, chronic obstructive pulmonary disease; $\mathrm{HCQ}$, hydroxychloroquine; HFpEF, heart failure with preserved ejection fraction; HFrEF, heart failure with preserved ejection fraction; HTN, hypertension; ICU, intensive care unit; LVEF, left ventricular ejection fraction; PCU, progressive care unit.

The mean and standard deviation are presented at the initial, 48-hour, and 5-day measurement times. Additionally, the differences $(\Delta)$ are presented for the initial-48-hour and initial-5-day comparisons. The one-sample $t$-tests showed statistically significant differences among all comparisons made except for the initial-5day $\Delta \mathrm{QT}$. The green category patients did not statistically differ from the red category value for this calculated $\Delta \mathrm{QTC}$.

Table 5 also shows the comparison of these QTc interval measurements between the green and yellow categories. A statistically significant difference was found for initial mean QTc interval and the QTc delta at 5 days between the patients in the green and yellow categories. When the yellow and green cate- 


\section{Risk of QT-Interval Prolongation From Off-Label COVID-19 Treatments: A Single-Center Experience}

\begin{tabular}{|c|c|c|c|}
\hline & Number & Mean & Standard Deviation \\
\hline QTC initial & 94 & 441.7 & 42 \\
\hline QTc $48 \mathrm{~h}$ & 74 & 450.5 & 46.8 \\
\hline QTC $5 \mathrm{~d}$ & 62 & 454.9 & 33.5 \\
\hline QTC $10 \mathrm{~d}$ & 21 & 460.1 & 37.7 \\
\hline$\triangle$ QTc $48 \mathrm{~h}$ & 71 & 8.6 & 53.4 \\
\hline$\triangle$ QTC $5 \mathrm{~d}$ & 61 & 13.4 & 40.3 \\
\hline$\Delta Q T C 10 \mathrm{~d}$ & 21 & 17.6 & 43.4 \\
\hline
\end{tabular}

gories were combined, the mean $\Delta \mathrm{QT} \mathrm{c}$ was $17.8 \mathrm{~ms}(P<.001)$, and only $14 \%$ of patients had a $\Delta Q T c$ greater than $60 \mathrm{~ms}$.

Of the 100 patients analyzed, there was 1 confirmed polymorphic ventricular tachycardia arrest. This patient was in the red risk category and experienced a prolongation of QTc interval greater than $60 \mathrm{~ms}$. Only 2 cardiac arrests were reported in the combined green-yellow category, which were not related to $\mathrm{TdP} / \mathrm{VF}$. Interestingly, patients in the combined green-yellow category did have several risk factors for QTc-interval prolongation, including $60 \%$ concomitantly receiving at least 1 QT-prolonging drug; and and at admission, $45 \%$ had a potassium level less than $4 \mathrm{mEq} / \mathrm{L}$, and $50 \%$ had a magnesium level less than $2 \mathrm{mg} / \mathrm{dL}$. In addition, the majority of our patients received both HCQ and azithromycin.

\section{DISCUSSION}

Evidence for the use of HCQ for COVID-19 comes from in vitro studies and from studies with small cohorts of patients. ${ }^{1-6}$ Although evidence was limited for therapies, $\mathrm{H} \pm \mathrm{A}$ was used routinely in many hospitals throughout the world. The severely ill population and those at higher risk of DI-SCD (QTc interval $>500 \mathrm{~ms}$ ) were generally excluded from even the limited trials, so safety evidence was limited for that group of patients.

On June 15, 2020, the Food and Drug Administration released a letter revoking the emergency use authorization for oral formulations of chloroquine phosphate and hydroxychloroquine sulfate due to concerns about low benefits and high risk, mostly of arrhythmic events. ${ }^{10}$ On the other hand, a recent publication in Lancet that concluded that $\mathrm{H} \pm \mathrm{A}$ was not only ineffective but also harmful in terms of QTc-interval prolongation and cardiac events has been retracted. ${ }^{11}$ Given conflicting information, further assistance for providers is needed. We sought to provide our experience within the safety of $\mathrm{H} \pm \mathrm{A}$ in patients with COVID-19.

In our experience, the rate of arrhythmic events was low overall, and only 1 patient experienced sudden cardiac arrest from QTc-interval prolongation. This patient was deemed highrisk, in the red category as per the Ackerman algorithm, and received both HCQ and azithromycin. Interestingly, patients in the green (low risk) and yellow (intermediate risk) categories did have several risk factors for QTc-interval prolongation; despite this, the change in QTc interval was generally very small.

Table 5. QTc Interval Value and Delta Comparisons Among Ackerman Algorithm Categories

\begin{tabular}{|c|c|c|c|c|c|c|}
\hline & \multicolumn{2}{|c|}{$\begin{array}{l}\text { QTc Initial, } \\
\text { Mean (SD) }\end{array}$} & $\begin{array}{l}\text { QTc } 48 \text { h, } \\
\text { Mean (SD) }\end{array}$ & $\begin{array}{l}\text { QTc } 5 \mathrm{~d} \text {, } \\
\text { Mean (SD) }\end{array}$ & $\begin{array}{l}\triangle \text { QTC (Initial-48 } \\
\text { h), Mean (SD) }\end{array}$ & $\begin{array}{l}\triangle Q T c \text { (Initial-5 d), } \\
\text { Mean (SD) }\end{array}$ \\
\hline Red Category Value & \multicolumn{2}{|c|}{533.5} & 630 & 569 & -118 & -14 \\
\hline Green-Yellow Combined $(n=92)$ & \multicolumn{2}{|c|}{$439.7(40.1)$} & $447.8(42.9)$ & $453.2(30.6)$ & $-6.9(52.1)$ & $-13.4(40.7)$ \\
\hline Yellow Only $(n=12)$ & \multicolumn{2}{|c|}{$486.8(8.34)$} & $491.5(75.4)$ & $446.1(15.9)$ & $-4.1(74.3)$ & $38.1(24.1)$ \\
\hline Green Only ( $n=80)$ & \multicolumn{2}{|c|}{$432.6(38.1)$} & $440.5(30.0)$ & $454.1(32.0)$ & $-7.4(48.3)$ & $-20.2(37.5)$ \\
\hline \multicolumn{7}{|c|}{ One-Sample $t$-Test } \\
\hline \multirow[t]{2}{*}{ Green-Yellow Combined } & $t$ & -22.5 & -35.6 & -44.8 & 17.8 & 0.11 \\
\hline & $P$ & $<.001$ & $<.001$ & $<.001$ & $<.001$ & .91 \\
\hline \multirow[t]{2}{*}{ Yellow Only } & $t$ & -19.4 & -5.8 & -20.4 & 4.8 & 5.7 \\
\hline & $P$ & $<.001$ & $<.001$ & $<.001$ & $<.001$ & $<.001$ \\
\hline \multirow[t]{2}{*}{ Green Only } & $t$ & -23.7 & -48.9 & -26.1 & 17.8 & -1.2 \\
\hline & $P$ & $<.001$ & $<.001$ & $<.001$ & $<.001$ & .23 \\
\hline \multicolumn{7}{|c|}{ Independent-Samples $t$-Test } \\
\hline \multirow[t]{2}{*}{ Yellow vs Green } & $t$ & 11.1 & 2.1 & -0.64 & 0.18 & 3.99 \\
\hline & $P$ & $<.001$ & .06 & .52 & .86 & $<.001$ \\
\hline
\end{tabular}




\section{COVID-QTC Continued from page 13}

And although we found a statistically significant difference in the initial mean QTc interval and the $\Delta \mathrm{QTc}$ at 5 days between the green and yellow categorized patients, in our opinion this difference is not clinically significant, and no arrhythmic events were reported among patients in these groups.

Overall, we feel that use of the Ackerman algorithm to iden-tify a patient's risk can be helpful in decision-making in regard to experimental treatment with $\mathrm{H} \pm \mathrm{A}$. Our data suggest that yellow and green categorized patients could have similar risk profiles. In our cohort of patients, there was a marked difference in clinical course between the red category vs the combined yellow and green categories, very much benign the latter cate-gory in terms of safety regarding DI-SCD. Future research should focus on increasing sample sizes of the groups to address statis-tical power to verify whether or not yellow and green categorized patients can be accurately grouped together for comparison with red categorized patients.

A major limitation of the study is the retrospective design. We are also limited by small sample size, particularly within the high-risk group. Given that there were only 2 patients in the red or high-risk category, the risk of DI-SCD may be overestimated, since we did have a patient in this group experience DI-SCD.

\section{CONCLUSION}

Current evidence is still not clear whether $\mathrm{H} \pm \mathrm{A}$ is effective for treatment of COVID-19. The strongest argument against its controversial use is the potential harm in terms of arrhythmic events. The aim of our study was to analyze the safety of $\mathrm{H} \pm \mathrm{A}$. According to our data, in patients in the yellow and green cat-egory as per the Ackerman algorithm, health care providers can have some reassurance in terms of safety, given that the patients did not have concerning QTc-interval prolongation or ventricular arrhythmias even when combined treatment $(\mathrm{H} \pm \mathrm{A})$ was used. Larger, prospective trials are needed to guide safe and effective COVID-19 pharmacological treatment.

\section{REFERENCES:}

1. Chen Z, Hu J, Zhang Z, et al. Efficacy of hydroxychloroquine in patients with COVID-19: results of a randomized clinical trial. MedRxiv. Preprint posted online April 10, 2020. doi:10.1101/2020.03.22.20040758

2. Wang M, Cao R, Zhang L, et al. Remdesivir and chloroquine effectively inhibit the recently emerged novel coronavirus (2019-nCoV) in vitro. Cell Res. 2020;30(3):269-271. doi:10.1038/s41422-020-0282-0

3. Gautret P, Lagier J-C, Parola P, et al. Hydroxychloroquine and azithromycin as a treatment of COVID-19: results of an open-label non-randomized clinical trial. Int J Antimicrob Agents. 2020;56(1):105949. doi:10.1016/j. ijantimicag.2020.105949

4. Yao X, Ye F, Zhang M, et al. In vitro antiviral activity and projection of optimized dosing design of hydroxychloroquine for the treatment of severe acute respiratory syndrome coronavirus 2 (SARS-CoV-2). Clin Infect Dis. 2020; 71(15):732-739. doi:10.1093/cid/ciaa237

5. Gautret P, Lagier J-C, Parola P, et al. Clinical and microbiological effect of a combination of hydroxychloroquine and azithromycin in 80 COVID-19 patients with at least a six-day follow up: a pilot observational study. Travel Med Infect Dis. 2020;34:101663. doi:10.1016/j.tmaid.2020.101663

6. Zhou D, Dai S-M, Tong Q. COVID-19: a recommendation to examine the effect of hydroxychloroquine in preventing infection and progression. J Antimicrob Chemother. 2020;75(7):1667-1670. doi:10.1093/jac/dkaa114

7. Woosley RL, Heise CW, Gallo T, Tate J, Woosley D, Romero KA. QTdrugs list. Accessed September 16, 2020. https://www.crediblemeds.org

8. Giudicessi JR, Noseworthy PA, Friedman PA, Ackerman MJ. Urgent guidance for navigating and circumventing the QTc-prolonging and torsadogenic potential of possible pharmacotherapies for coronavirus disease 19 (COVID-19). Mayo Clin Proc. 2020;95(6):1213-1221. doi:10.1016/..mayocp.2020.03.024

9. ARDS Definition Task Force. Acute respiratory distress syndrome: the Berlin Definition. JAMA. 2012;307(23):2526-2533. doi:10.1001/jama.2012.5669

10. FDA cautions against use of hydroxychloroquine or chloroquine for COVID-19 outside of the hospital setting or a clinical trial due to risk of heart rhythm problems. FDA Drug Safety Communication. US Food and Drug Administration. April 24, 2020. Updated June 15, 2020. Accessed September 16, 2020. https://www.fda.gov/media/136784

11. Mehra MR, Desai SS, Ruschitzka F, Patel AN. Hydroxychloroquine or chloroquine with or without a macrolide for treatment of COVID-19: a multinational registry analysis. Lancet. Published online May 22, 2020. Retracted in: Lancet. 2020;395(10240):1820. doi:10.1016/S0140-6736(20)31324-6 